\title{
The Macroeconomic Impact of Unconventional Monetary Policy Shocks
}

\author{
Annette Meinusch* \\ Justus-Liebig-University Gießen, Germany
}

\author{
Peter Tillmann ${ }^{\dagger}$ \\ Justus-Liebig-University Gießen, Germany
}

March 28, 2014

\begin{abstract}
With the Federal Funds rate approaching the zero lower bound, the U.S. Federal Reserve adopted a range of unconventional monetary policy measures known as Quantitative Easing (QE). Quantifying the impact QE has on the real economy, however, is not straightforward as standard tools such as VAR models cannot easily be applied. In this paper we use the Qual VAR model (Dueker, 2005) to combine binary information about QE announcements with an otherwise standard monetary policy VAR. The model filters an unobservable propensity to QE out of the observable data and delivers impulse responses to a $\mathrm{QE}$ shocks. In contrast to other empirical approaches, $\mathrm{QE}$ is endogenously depending on the business cycle, can easily be studied in terms of unexpected policy shocks and its dynamic effects can be compared to a conventional monetary easing. We show that QE shocks have a large impact on real and nominal interest rates and financial conditions and a smaller impact on real activity.
\end{abstract}

Keywords: Qual VAR, unconventional monetary policy, LASP, zero lower bound, quantitative easing

JEL classification: E32, E44, E52

\footnotetext{
*Email: annette.meinusch@wirtschaft.uni-giessen.de
}

†Email: peter.tillmann@wirtschaft.uni-giessen.de 


\section{Motivation}

In the wake of the recent financial crisis, the policy rates of almost all central banks in industrialized countries reached the zero lower bound of nominal interest rates, and will remain at historically low levels for the time being. Nominal interest rates near their lowest possible level create a challenge for central banks leaving little or, in fact, no room for further cuts to provide stimulus to the financial sector and the wider economy when necessary.

Facing this limitation central banks such as the U.S. Federal Reserve introduced Quantitative Easing (QE) measures to implement a further monetary stimulus. Quantitative Easing covers actions that expand the central bank's balance sheet such as large-scale asset purchases (LSAP) and those that change the maturity composition of the Fed's bond portfolio, i.e. the Maturity Extension program also known as "Operation Twist". Another powerful instrument of the central bank's unconventional toolkit is a measure known as Forward Guidance. It is a communication strategy that has the ability to explicitly guide market expectations and reduce policy uncertainty by enhancing the predictability of monetary policy decisions. As a result of Forward Guidance, the expectations component of long-term rates should fall. In the case of the Fed, Forward Guidance has been used not only to provide markets with a future path of the nominal interest rate, which was announced to remain at zero, but also to ascertain a path of future asset purchases to further increase the Fed's balance sheet.

While the Federal Reserve started to gradually reduce, i.e. 'taper', its program of monthly purchases of government and mortgage bonds in late 2013/early 2014, expectations are mounting that the European Central Bank may soon adopt a quantity-based program to stimulate the sluggish euro-area economy. Against this background, the central question from both a policy and a research perspective is how $\mathrm{QE}$ actions affect fundamentals. In this paper, we want to give a quantitative answer to this question.

For macroeconomists who intend to analyze monetary policy, vector autoregressive (VAR) models introduced by Sims (1980) are the tool of first choice. However, unconventional monetary policy measures such as QE actions pose a challenge to standard VAR analysis. Since there is no single policy instrument whose variation reflects unconventional policy steps, QE measures are often modeled as a binary indicator which could be used, for example, for event study regressions but which cannot easily be implemented in a conventional VAR model. Likewise, QE steps are likely to be endogenously depending on the state of the business cycle and cannot 
simply be modelled as dummy variables only.

We offer an alternative approach to estimate the impact of QE on the macroeconomy. The model integrates the information from the announcements of QE into an otherwise standard monetary policy VAR. One can think of the observable binary indicator of QE actions as a variable behind which lies a continuous latent, i.e unobservable variable, reflecting the propensity to unconventional monetary policy. The resulting model is a Qual VAR (Dueker, 2005). Based on the dynamic interaction within the VAR model, Markov Chain Monte Carlo techniques can filter this latent variable out of the data which then provides us with a continuous series on monetary policy's propensity to QE. Next, this variable enters the VAR model as a regressor and enables the derivation of impulse response functions.

The advantages of the Qual VAR are fourfold: first, we take explicit account of the endogenous nature of Quantitative Easing. Rather than including QE announcements as an exogenous variable in an event study or a panel model, we model the interaction with business cycle variables - very much like in a standard monetary policy VAR. Second, since we eventually estimate a standard VAR, we can discuss the effects of policy in terms of shocks. That is, we focus on the unexpected part of QE only. Third, the model provides a way to link macroeconomic, i.e. low-frequency data to QE announcement days which are often modelled as a binary variable. Fourth, since we can use impulse response analysis, again very much like in the standard monetary policy VAR literature, we can directly compare the dynamic effect of a QE shock with that of a conventional monetary easing.

The model is estimated on U.S. data since the end of 2007. We extract a very plausible evolution of the Fed's latent propensity to enter QE. The resulting impulse response functions suggest that QE does indeed have a significant and sizable effect on both real economic activity and the financial sector. Shocks to QE raise industrial production and employment and lower nominal and real long-term interest rates, respectively. Furthermore, QE shocks push equity returns and reduce financial market uncertainty as reflected by the CBOE volatility index (VIX). We are also able to track the impact of QE over time. While QE1 had only a small effect on all variables mentioned before, the effects of QE2 and QE3 were substantially larger. For example, stock returns in 2011 were almost entirely explained due to the impact of QE.

The remainder of this article is organized as follows. Section 2 gives account of previous empirical work on the effects of $\mathrm{QE}$ and explains in what sense this paper improves upon previous research. Section 3 lays out the empirical methodology. The data set and the alternative model specifications are introduced in Section 4 . Our 
results are discussed in Section 5. Section 6 compares the results to conventional monetary policy shocks. Finally, Section 7 draws some conclusions.

\section{The effects of QE: what do we know?}

Over the recent years, the empirical literature on the effectiveness of unconventional monetary policy grew in tandem with the Fed's balance sheet. When it comes to quantifying the effects of $\mathrm{QE}$, however, the basic difficulty is that there is no well-defined policy instrument whose variation indicates the Fed's policy stance and which is easily observable. Over the past 30 years the monetary policy literature had agreed to interpret the Federal Funds rate as the Fed's main instrument for conventional monetary policy. With the Fed Funds rate at zero, however, it no longer serves this purpose.

One way to provide an overview over the relevant literature is to argue that the empirical literature differs in the choice of the policy instrument used to measure unconventional policies. The biggest strand of the literature focuses on the announcements of QE measures themselves. ${ }^{1}$ Often, high frequency data is used to study the immediate response of financial variables to QE surprises. These surprises are extracted from futures markets. The most important contributions to the eventstudy literature are Gagnon et al. (2011), Krishnamurty and Vissing-Jorgensen (2011), D'Amico et al. (2012), Glick and Leduc (2013) and Neely (2013). It is typically found that domestic interest rates fall upon a QE announcement. In addition, the USD weakens against major currencies. ${ }^{2}$ The problem with this line of research is that it is confined to financial data only. Linking macroeconomic variables to QE announcements while controlling for business cycle dynamics is difficult. The approach proposed in this paper, however, is able to proceed along these lines. Furthermore, the size and the timing of unconventional policy actions are endogenous and reflect the business cycle. Thus, the model should allow for a feedback from macroeconomic variables to policy actions.

Another strand uses the Fed's balance sheet directly. Gambacorta et al. (2013) estimate a panel VAR model consisting of countries that adopted QE such as the US, the euro area and Japan. QE shocks are identified using sign restrictions requiring, among other things, an immediate increase in the Fed's balance sheet following a QE shock. ${ }^{3}$ The advantage is that this approach allows the inclusion of macroeconomic

\footnotetext{
${ }^{1}$ For a critical view on the event-study evidence on the effectiveness of QE see Thornton (2013).

${ }^{2}$ Wright (2012) offers an SVAR model in which QE shocks are identified using volatility clustering on announcement days. Neely (2014), however, questions the stability of this VAR model.

${ }^{3}$ Schenkelberg and Watzka (2013) also use sign restrictions to study the effects of unconventional
} 
variables - very much as in our approach. The drawback, however, is that not all QE measures directly lead to an increase in the balance sheet of the central bank. "Operation Twist" or the announcement of an entire path of future asset purchases either leave the balance sheet unchanged or lead to a small increase only. The total impact of the entire future stream of asset purchases might not be fully reflected in today's balance sheet.

As QE most likely reduces long term interest rates, another strand of the literature uses either the long rate or the spread between long and short rates as a policy instrument. For example, Gilchrist et al. (2013) use the two year nominal treasury yield as an instrument. They find a significant reduction in real borrowing costs following a reduction of the policy instrument. Chen et al. (2012) use the term spread as the policy variable within a global vector error-correction model for a large set of countries. In a very interesting paper, Baumeister and Benati (2013) estimate a time-varying VAR model in which a spread shock is identified that leaves the policy rate unchanged. They show that the Fed's and the Bank of England's unconventional measures have avoided a large, Great Depression-like output collapse.

Our paper is also related to recent endeavors to uncover a latent policy stance from observables if the usual policy instrument is stuck at the zero lower bound. Examples include Lombardi and Zhu (2014), who derive a shadow policy rate from a dynamic factor model. Hamilton and Wu (2012), Christensen and Rudebusch (2013) and Wu and Xia (2014) extract the Fed's shadow policy rate from nonlinear term structure models.

In this paper, we propose to study the effects of unconventional monetary policies on the macroeconomy by employing Dueker's (2005) Qual VAR model that originally was used to forecast business cycle turning points. In doing so, we combine a binary choice model with the workhorse method to analyze monetary policy and its implications - the VAR model. This allows us to integrate QE announcements into an otherwise standard monetary policy VAR model and to uncover the Fed's latent propensity for Quantitative Easing.

\section{The estimation of a Qual VAR in a nutshell}

In this section we explain the econometric specifications of Dueker's (2005) multivariate dynamic probit model, also referred to as a Qual VAR. As a first component

monetary policy by the Bank of Japan since the mid-1990s. A quantitative easing shock leads to a significant decrease in long-term interest rates and significantly increases output and the price level. 
of the model, we consider a latent variable $y_{t}^{*}$ as shown in equation (1) to determine unconventional monetary policy measures. It is defined as an autoregressive variable depending on its own lagged value and a set of explanatory variables $X_{t-1} ; \phi$ and $\beta$ are a scalar and a vector of the coefficients, respectively; $\epsilon_{t}$ is a random error term following standard normal distribution and $t=1, \ldots, T$ is the time index

$$
y_{t}^{*}=\phi y_{t-1}^{*}+\beta X_{t-1}+\epsilon_{t}, \quad \epsilon_{t} \sim \mathcal{N}(0,1)
$$

We assign the value of one to a binary variable $y_{t}$ if unconventional policy actions (QE) occur in period $t$ and zero otherwise. Using equation (1), the value of the binary variable $y_{t}$ takes the form

$$
y_{t}= \begin{cases}0 & \text { if } y_{t}^{*} \leq 0 \\ 1 & \text { if } y_{t}^{*} \geq 0\end{cases}
$$

The second component of the model is a $\operatorname{VAR}(\rho)$ process for the dynamics of $k$ regressors

$$
Y_{t}=\mu+\sum_{l=1}^{\rho} \Phi^{(l)} Y_{t-l}+\nu_{t}, \quad \nu_{t} \sim \mathcal{N}(0, \Sigma)
$$

with a $k \times 1$ vector $Y_{t}=\left(X_{t}, y_{t}^{*}\right)^{\prime}$ where $X_{t}$ incorporates $k$-1 time series of observed macroeconomic data and $y_{t}^{*}$ constitutes a vector of the latent variable. The set of VAR coefficients is described by

$$
\Phi^{(l)}=\left[\begin{array}{ll}
\Phi_{X X}^{(l)} & \Phi_{X y^{*}}^{(l)} \\
\Phi_{y^{*} X}^{(l)} & \Phi_{y^{*} y^{*}}^{(l)}
\end{array}\right],
$$

$\mu$ is a $k \times 1$ vector of constants and $\nu_{t}$ constitutes the $k \times 1$ error vector. The covariance matrix of the errors is $\Sigma$.

Hence, the complete Qual VAR system comprises the linear relation between the latent variable, which below will be interpreted as the Fed's propensity for QE, and the regressors, see equation (1), the mapping with the binary observation, equation (2) and the VAR representation, equation (3).

Dueker (2005) and Assenmacher-Wesche and Dueker (2010) show that the model can be estimated by Markov Chain Monte Carlo (MCMC) techniques, in particular via Gibbs Sampling. Gibbs Sampling enables the joint estimation of the VAR coefficients $\Phi$, the covariance matrix of the VAR residuals $\Sigma$ and the latent variable $y_{t}^{*}$. For this purpose the iterative algorithm generates a sequence of draws from the following 
conditional distributions

VAR coefficients $\sim$ Normal

$$
\pi\left(\Phi^{(i+1)} \quad \mid \quad\left\{y_{t}^{*(i)}\right\}_{t=1, \ldots, T},\left\{X_{t}\right\}_{t=1, \ldots, T}, \Sigma^{(i)}\right)
$$

Covariance matrix $\sim$ inverted Wishart

$$
\left.\pi\left(\Sigma^{(i+1)}\right) \quad \mid \quad\left\{y_{t}^{*(i)}\right\}_{t=1, \ldots, T},\left\{X_{t}\right\}_{t=1, \ldots, T}, \Phi^{(i+1)}\right)
$$

Latent variable $\sim$ truncated Normal

$$
\pi\left(y_{t}^{*(i+1)} \mid\left\{X_{t}\right\}_{t=1, \ldots, T},\left\{y_{j}^{*(i+1)}\right\}_{j<t},\left\{y_{k}^{*(i)}\right\}_{k>t}, \Phi^{(i+1)}, \Sigma^{(i+1)}\right) .
$$

Under the Jeffrey's prior the conditional posterior for the VAR coefficients will be multivariate Normal and the conditional posterior of the variance will be Wishart distributed. In each period a single observation of the latent variable is truncated Normal with truncation limits that are imposed by the observable binary variable $y_{t}$.

For a sufficiently large number of iterations $i$, the obtained draws constitute the true joint posterior distribution. Thus, Gibbs Sampling only requires knowledge of the full conditional posterior distribution of the VAR coefficients $\Phi$, the covariance matrix $\Sigma$ and the latent variable $y_{t}^{*}$.

Several remarks concerning our estimation are in order here. In each iteration cycle we generate a draw for the latent variable by first setting up a state space model. The state equation is expressed as

$$
\begin{aligned}
{\left[\begin{array}{c}
y_{t}^{*} \\
y_{t-1}^{*} \\
y_{t-2}^{*} \\
\vdots \\
y_{t-\rho+1}^{*}
\end{array}\right]=} & {\left[\begin{array}{c}
c_{y^{*}} \\
0 \\
0 \\
\vdots \\
0
\end{array}\right]\left[\begin{array}{ccccc}
\Phi_{y^{*} y^{*}}^{(1)} & \Phi_{y^{*} y^{*}}^{(2)} & \Phi_{y^{*} y^{*}}^{(3)} & \ldots & \Phi_{y^{*} y^{*}}^{(\rho)} \\
1 & 0 & 0 & \ldots & 0 \\
0 & 1 & 0 & \ldots & 0 \\
\vdots & \vdots & \ddots & & 0 \\
0 & 0 & \ldots & 1 & 0
\end{array}\right]\left[\begin{array}{c}
y_{t-1}^{*} \\
y_{t-2}^{*} \\
y_{t-3}^{*} \\
\vdots \\
y_{t-\rho}^{*}
\end{array}\right] } \\
+ & {\left[\begin{array}{ccc}
\Phi_{y^{*} X}^{(1)} & \ldots & \Phi_{y^{*} X}^{(\rho)} \\
0 & \ldots & 0 \\
0 & \ldots & 0 \\
\vdots & \vdots & \vdots \\
0 & \ldots & 0
\end{array}\right]\left[\begin{array}{c}
X_{t-1} \\
X_{t-2} \\
X_{t-3} \\
\vdots \\
X_{t-\rho}
\end{array}\right]+\left[\begin{array}{c}
\epsilon_{y^{*}, t} \\
0 \\
0 \\
\vdots \\
0
\end{array}\right] }
\end{aligned}
$$

with the following measurement equation 


$$
y_{t}^{*}=\left[\begin{array}{lllll}
1 & 0 & 0 & \ldots & 0
\end{array}\right]\left[\begin{array}{c}
y_{t}^{*} \\
y_{t-1}^{*} \\
y_{t-2}^{*} \\
\vdots \\
y_{t-\rho}^{*}
\end{array}\right]
$$

Secondly, we apply Kalman Smoothing in order to determine the mean and the variance of the states e.g. the latent variable, conditional on past and future values of it and also conditional on the macroeconomic data. The Smoother requires initial values that are obtained from the binary data for the latent variable and from OLS estimates for the coefficients given the binary data. Based on the first two moments a latent variable for each period is drawn from the truncated Normal. For the pre-sample draws of the latent variable that constitutes the first $\rho$ periods, Dueker (2005) proposes an Accept-Reject Metropolis-Hastings (AR-MH) algorithm. We, however, start the Kalman Smoother in period $\rho-1$, e.g. one period before the working start of the data and generate conditional draws from a small multivariate Normal.

Thirdly, in each iteration we estimate the VAR in equation (3) given the sampled time series of the latent variable and obtain OLS estimates for $\Phi$ and $\Sigma$ denoted by $\hat{\Phi}$ and $\hat{\Sigma}$. Based on this information and the assumed Jeffrey's prior a draw for $\Sigma$ is made from the inverted Wishart distribution with $T-k$ degrees of freedom where $T$ is the number of observations, $k$ the number of explanatory variables and $(T \hat{\Sigma})^{-1}$ describes the covariance from OLS

$$
\Sigma \sim \mathcal{I} \mathcal{W}\left\{(T \hat{\Sigma})^{-1}, T-k\right\}
$$

Eq.(1) shows that the variance of the latent variable is 1 . We take this into account by equally adjusting the appropriate element in $\Sigma$ and by normalizing the other elements in the corresponding column.

Given $\Sigma$ we obtain a draw for $\Phi$ by adding the mean from the OLS estimates to a draw from a multivariate Normal distribution with a covariance matrix that is denoted by the Kronecker product of the draw for $\Sigma$ and $\left(Y^{\prime} Y\right)^{-1}$

$$
\Phi \sim \mathcal{N}\left\{\hat{\Phi}, \Sigma \otimes\left(Y^{\prime} Y\right)^{-1}\right\}
$$

In each estimation the Gibbs Sampler was run for a total of 2,000 iterations with 1,000 initial iterations that were discarded to not only allow the sampler to converge 
to the posterior distribution but also to be less dependent on the initial values. Our estimates did not differ significantly using a higher number of burn-in iterations. Draws of the VAR coefficients from the OLS distribution that were not stationary and thus implied a unit root were rejected and resampled. From the resulting sample of 1,000 iterations, we calculate the mean of the latent variable, the VAR coefficients and the variance.

The Qual VAR as a forecasting model has been applied by Bordo et al. (2007), Amstad et al. (2008) and Assenmacher-Wesche and Dueker (2010). Dueker (2005) discusses the response of the economy to Romer-dates, i.e. binary information on policy tightening derived from FOMC transcripts. We provide the first application to unconventional monetary policy.

\section{Data}

We estimate the Qual VAR on monthly U.S. data over a sample period from 2007:08 to 2013:03. Since the Fed announced the first round of QE in late 2008, the sample from the start of QE1 to the end of QE3 is inevitably fairly short. At the same time, however, estimating a VAR system requires sufficient degrees of freedom. We address this concern by starting the sample roughly a year before the Lehman collapse. Although at that time adjusting the Federal Funds rate as the Fed's main policy instrument was still feasible, we include this period to extent our sample. Since the rationale for the drastic interest rate cuts in 2007-2008 was maintaining financial stability, these interest steps in some sense already reflected a non-standard monetary policy easing. Therefore, we consider including these observations and thereby improving the efficiency of the estimation is justified. Gambacorta et al. (2013) also start their panel VAR in 2008:01, i.e. before the inception of unconventional policy measures.

We feed the Qual VAR with a set of four endogenous variables. We restrict ourselves to just four variables in light of the short sample period. That also forces us to use data which is available on a monthly frequency. As a robustness check, however, we will report the results from various alternative combinations of these variables below. Furthermore, we estimate the model in first differences instead of (frequently used) $\log$ levels for two reasons. First, the variables have to be stationary in order to be consistent with the assumptions in the MCMC estimations. Second, growth rates appear to be more consistent with the idea of the latent variable reflecting the propensity to easing - that is, with the accumulated latent series indicating the stance of unconventional monetary policy. 
In a standard VAR, information criteria are used to determine the appropriate lag lengths. Since these criteria are defined for non-binary data only, they are not meaningful in our case. Therefore, we start with including four lags in our Qual VAR system. This number is, again, chosen with an eye on the short sample that we have available. Below we also report results for alternative lag orders.

The first variable to include is a binary index of QE announcements. This index is equal to one in months with an important $\mathrm{QE}$ announcement and zero otherwise. To construct this index, we use the dates given in table (1). These include all important announcements of QE1, QE2, QE3 and the Maturity Extension Programme, either being speeches of Chairman Bernanke, minutes released from FOMC meeting or FOMC announcements. This binary variable together with the remaining variables in the $X_{t}$ vector are used to derive the latent propensity for Quantitative Easing, $y_{t}^{*}$.

Besides the binary QE indicator we include three U.S. macro variables that are among the variables that are either closely watched by policymakers or explicitly targeted by unconventional measures. The first variable is a measure of real economic activity. We choose the year-on-year growth rate of the index of industrial production $(\Delta \mathrm{IP})$. In an alternative specification, we replace this variable with the growth rate of total nonfarm private payroll employment $(\Delta \mathrm{EMP})$. Both variables are taken from FRED at the Federal Reserve Bank of St. Louis. The second variable is the nominal 10-year Treasury constant maturity rate (Yield). As an alternative, we will use the yield on Treasury Inflation Index Securities (TIPS) or the long-term real interest rate (RIR), which is measured as the 10-year Treasury constant maturity rate minus the median 10-year inflation expectations taken from the Survey of Professional Forecasters, accessed through the website of the Federal Reserve Bank of Philadelphia. We do not incorporate the inflation rate since the implementation of unconventional policies was not guided by concerns about inflation considerations. Finally, we include a variable reflecting the financial markets' impact of QE. We choose either the year-on-year growth rate of the CBOE Volatility Index of implied stock market volatility $(\Delta \mathrm{VIX})$ or the rate of change of the S\&P 500 U.S. stock market index $(\triangle \mathrm{STOCKP})$, again both taken from FRED. The former is often interpreted as a measure of financial market uncertainty. The latter captures the likely impact of QE on asset markets.

To summarize our different models, the vector of variables for our baseline Qual VAR is $Y_{t}=\left(X_{t}, y_{t}^{*}\right)^{\prime}$ where the following variables are included: 


\begin{tabular}{ll}
\hline model I: & $X_{t}^{\prime}=(\Delta I P$, Yield,$\Delta V I X)$ \\
model II: & $X_{t}^{\prime}=(\Delta I P, R I R, \Delta V I X)$ \\
model III: & $X_{t}^{\prime}=(\Delta I P$, TIPS,$\Delta V I X)$ \\
model IV: & $X_{t}^{\prime}=(\Delta I P$, Yield,$\Delta S T O C K P)$ \\
model V: & $X_{t}^{\prime}=(\Delta E M P$, Yield,$\Delta V I X)$ \\
\hline
\end{tabular}

Since the adoption of QE was guided by the Federal Reserve's desire to improve firms' long-term refinancing costs and, as a result of that, foster the economic recovery, we expect our measure of real activity to increase after a QE shock. The long-term interest rate should fall after a shock while the VIX should also fall.

The Qual Var methodology shown in section 3 allows to apply standard VAR tools such as impulse response functions and historical decompositions. For this purpose the QE shock has to be identified. Over the past 30 years a huge literature discusses the appropriate scheme to identify monetary policy shocks. Here, we follow Christiano et al. (1999) and adopt the most standard approach. We use a Cholesky decomposition based on the following ordering of variables: IP, $y_{t}^{*}$, RIR, VIX. This implies that within a month unconventional monetary policy affects the real interest rate and the VIX but not industrial production. Likewise, monetary policy is allowed to respond to industrial production within a given month. Below we also check the robustness of our findings with regard to the ordering of the variables.

\section{Results}

The results of the Qual VAR estimation are presented in three steps. We first discuss the estimated latent variable behind the observable QE announcements. This variable is interpreted as the Fed's propensity to QE. Then we present the estimated impulse response functions. Finally, a historical decomposition of the VAR model is used to illustrate the explanatory power of QE shocks over time.

\subsection{The Fed's propensity to QE}

Figures (1) to (5) show the estimated latent propensity to QE. As a matter of fact, this series is required to be positive at each of the announcement dates which in the graphs are depicted as shaded areas. The model clearly uncovers mounting pressure before each announcement date which is reflected in sharp increases in the latent QE propensity. Furthermore, the intensity of the propensity for QE differs between announcement days. While the series reach their maximum level in late 2008 
at the initialization of QE1, the subsequent QE episodes result from a somewhat weaker propensity. This is probably due to QE being endogenous and reflecting fundamentals, most likely the sudden increase in the VIX in late 2008. Finally, the series of QE propensities are very similar across estimated models, which also underlines the robustness of these findings.

The latent propensity to QE can also be interpreted as the change in the Fed's policy stance. Hence, the stance can be derived by cumulating the latent propensity over time. One way to assess the quality of the Qual VAR in describing Fed policy is to compare this indicator of the policy stance with the shadow Federal Funds rate estimated by $\mathrm{Wu}$ and Xia (2014). The shadow rate is of course persistently negative since mid 2009. Figure (6) plots the policy stance derived from the Qual VAR against the inverted shadow rate. ${ }^{4}$ It can be seen that the latent stance tracks the evolution of monetary conditions reflected in the shadow rate quite well. The strong easing in 2009 as well as the slight reversal in early 2012 are clearly present in both series. The correlation between both indicators is 0.8 . We interpret this as a further confirmation of our model's strength.

\subsection{The response to QE shocks}

Once the latent variable is uncovered through MCMC estimation, the VAR coefficients are available and standard impulse response functions can be derived based on the Cholesky identification discussed before. Figures (7) to (11) show the dynamic responses of all endogenous variables to a QE shock, that is, an unexpected increase in the propensity to QE by one standard deviation. It is important to note that this perspective is most likely underestimating the policy impact on the announcement days. The reason for this is that on a specific date with a $\mathrm{QE}$ announcement the standard deviation of the latent propensity is much larger than the full sample standard deviation. All impulse responses are shown together with $90 \%$ bootstrapped confidence bands reflecting the estimation uncertainty of the VAR coefficient matrix.

In all models, an unconventional easing of monetary conditions raises the growth rate of industrial production or employment, respectively. A year after the policy impulse industrial production grows by one percentage point. The response of employment growth, however, is smaller, about 0.4 percentage points, and occurs a bit later, see figure (11). Within two month after the QE shock, long-term interest rates, both nominal and real, have fallen by about 0.15 percentage points. This response is highly significant. The similarity in the response patterns of the nominal bond

\footnotetext{
${ }^{4}$ The shadow rate is downloadable at http://faculty.chicagobooth.edu/jing.wu/.
} 
yield and the first measure of the real interest rate in models I and II suggests that long-term inflation expectations as reflected in the SPF's mean 10-year inflation projection do not appear sensitive to QE. Taken together, QE shocks do indeed have the intended consequences of stimulating the real economy and reducing firms' long-term refinancing conditions.

The figures also depicts the response of the change in the index of implied stock market volatility. This frequently used measure of financial instability falls by 10 percentage points within a year after the easing announcement. Thus, QE not only pushed the real economy but also calmed financial markets. As expected, the change in stock prices included in model IV, see figure (10), responds positively and peaks after 10 months. A shock to QE raises nominal stock returns by four percentage points.

\subsection{The explanatory power of QE shocks}

Based on the VAR estimates, the model could be used to back out two scenarios for the evolution of the endogenous variables. In the first scenario, the QE shock is present and, together with the other shocks, drives the economy. In a counterfactual, the QE shock is switched off. The difference between both outcomes thus illustrates the impact of QE shocks over time. Figures 12 to 16 plot the QE impact (in green) together with the realization of each observable variable (in red). These historical decompositions show that QE was indeed supportive to industrial production - again with a time lag of roughly one year - in each of the QE programs. Following QE2, the effect was strongest with the entire growth in industrial production being due to QE shocks.

In all model specifications, QE shocks also account for a sizable portion of the nominal and real interest rate, respectively. About half a percentage point is taken off the interest rate through QE shocks. Again, QE2 and QE3 seems to be more effective in this respect than QE1. Throughout the sample period QE shocks lower the VIX by about 25 percentage points. QE shocks also explain a large part of equity returns, see figure (15). Between 10 to 20 percentage points of the increase in stock prices is accounted for by QE shocks. In 2011, almost the entire stock market development is driven by QE shocks. 


\section{A comparison with conventional monetary pol- icy}

In this section we assess how unconventional the effect of unconventional monetary policy is, that is, we compare unconventional with conventional monetary policy. Before 2008, the Fed's main policy instrument was the Federal Funds rate. As a consequence, we estimate our model specification IV for the period 1998:1 to 2006:12 and replace the latent propensity to QE with the Federal Funds rate. All other model properties remain unchanged to facilitate a comparison of the results. In particular, the ordering of the variables is left untouched. We also leave the lag order unchanged and we do not include the inflation rate. The latter point is likely to result in an inappropriate representation of monetary policy before the crisis. Nevertheless, we leave out inflation in order to stay as close as possible to our model for QE.

The resulting impulse response functions describing the variables' adjustment after an unexpected policy easing are presented in figure (17). Most obviously, an expected policy easing results in a persistent fall in the Federal Funds rate. It can also be seen that industrial production increases reaching the peak response of $0.2 \%$ one year after the shock. Stock prices jump immediately by about two percentage points. This response, however, is likely to be misleading as in this model we neglect the inflation response. With an increase in inflation after a policy easing the real stock price movement will be more moderate. The long-term interest rate one year after the shock has fallen by 0.05 percentage points.

Since a one standard deviation increase in the latent propensity to QE in terms of magnitude is not directly comparable to a one standard deviation fall in the Federal Funds rate, we normalize the responses by the response in bond yields. In the Qual VAR an easing shock was consistent with a reduction of long rates of about 18 percentage points, which is roughly three times the response of the long rate after a one standard deviation fall in the Federal Funds rate. When considering the real impact of policy, we therefore see that QE has a larger impact than conventional policy. A policy impulse that is equivalent in terms of the impact on bond yields would thus lead to a one percent increase in industrial production when policy is implemented through QE and to only a $0.6 \%$ increase if policy is implemented in the conventional way. 


\section{Conclusions}

In this paper we proposed a new approach to estimate the impact of unconventional monetary policy. We find that a $\mathrm{QE}$ has significant effects on interest rates, real economic activity, stock prices and market uncertainty. We also showed that QE shocks account for a large fraction of the dynamics in stock prices and interest rates since 2008. QE is found to be even more effective in influencing real activity than conventional monetary policy. Our results thus provide empirical support to using unconventional policy tools.

Our model is based on the idea of linking standard business cycle dynamics reflected in a VAR system with binary information on QE announcement days. The resulting Qual VAR is able to extract the latent propensity to unconventional policy easing. The new model proposed here has several advantages over other approaches to estimating QE. In particular, its close similarity with standard VAR models make it an easy tool for policy analysis.

In our model we considered announcements to introduce or extend QE only. We did not, however, include announcements of exiting from QE or "tapering" unconventional measures, respectively. Given the recent market sensitivity to tapering news, applying the model to tapering events might be an interesting way forward. 


\section{References}

[1] Amstad, M., K. Assenmacher-Wesche and M. Dueker (2008): "Forecasting macroeconomic variables with a categorical latent variable based on the ISM index", unpublished, Swiss National Bank.

[2] Assenmacher-Wesche, K. and M. Dueker (2010): "Forecasting macro variables with a Qual VAR business cycle turning point index", Applied Economics 42, 2909-2920.

[3] Baumeister, C. and L. Benati (2013): "Unconventional monetary policy and the Great Recession: estimating the macroeconomic effects of a spread compression at the zero lower bound", International Journal of Central Banking, June 2013, 165-212.

[4] Bordo, M. D., M. J. Dueker and D. C. Wheelock (2007): "Monetary policy and stock market booms and busts in the 20th century", Working Paper 200\%-020A, Federal Reserve Bank of St. Louis.

[5] Chen, Q., A. Filardo, D. He and F. Zhu (2012): "International spillovers of central bank balance sheet policies", BIS Papers No. 66, 230-274, Bank for International Settlements.

[6] Christensen, J. H. E. and G. D. Rudebusch (2013): "Modeling yields at the zero lower bound: are shadow rates the solution?", Working Paper No. 201339, Federal Reserve Bank of San Francisco.

[7] Christiano, L. J., M. Eichenbaum and C. L. Evans (1999): "Monetary policy shocks: what have we learned and to what end?", in J. B. Taylor and M. Woodford (eds.), Handbook of Macroeconomics, Elsevier, New York.

[8] D'Amico, S. W. English, D. Lopez-Salido and E. Nelson (2012): "The Federal Reserve's large-scale asset purchase programs: rationale and effects", Finance and Economics Discussion Paper No. 2012-85, Board of Governors of the Federal Reserve.

[9] Dueker, M. (2005): "Dynamic forecasts of qualitative variables: a Qual VAR model of U.S. recessions", Journal of Business and Economic Statistics 23, 96-104.

[10] Fawley, B. W. and C. J. Neely (2013): "Four stories of Quantitative Easing", Federal Reserve Bank of St. Louis Review, January/February 2013, 51-88. 
[11] Gagnon, J., M. Raskin, J. Remache and B. Sack (2011): "The financial market effects of the Federal Reserve's large-scale asset purchases", International Journal of Central Banking 7, 4-43.

[12] Gambacorta, L., B. Hofmann and G. Peersman (2013): "The effectiveness of unconventional monetary policy at the zero lower bound: a cross-country analysis", forthcoming, Journal of Money, Credit and Banking.

[13] Gilchrist, S., D. Lpez-Salido and E. Zakrajsek (2013): "Monetary policy and real borrowing costs at the ZLB", unpublished, Boston University.

[14] Glick, R., S. Leduc (2013): "The effects of unconventional and conventional U.S. monetary policy on the dollar", Working Paper No. 2013-11, Federal Reserve Bank of San Francisco.

[15] Hamilton, J. and C. Wu (2012): "The effectiveness of alternative monetary policy tools in a zero lower bound environment", Journal of Money, Credit, and Banking 44, 3-46.

[16] Krishnamurty, A. and A. Vissing-Jorgensen (2011): "The effects of Quantitative Easing on on interest rates: channels and implications for policy", Brookings Papers on Economic Activity Fall 2011, 215-265.

[17] Lombardi, M. and F. Zhu (2014): "Filing the gap: a factor-based shadow rate to gauge monetary policy", unpublished, Bank of International Settlements.

[18] Neely, C. J. (2013): "Unconventional monetary policy had large international effects", Working Paper No. 210-013D, Federal Reserve Bank of St. Louis.

[19] Neely, C. J. (2014): "How persistent are monetary policy effects at the zero lower bound?", Working Paper No. 2014-004A, Federal Reserve Bank of St. Louis.

[20] Schenkelberg, H. and S. Watzka (2013): "Real effects of quantitative easing at the zero lower bound: structural VAR-based evidence from Japan", Journal of International Money and Finance 33, 327-357.

[21] Sims, C. A. (1980): "Macroeconomics and reality", Econometrica 48, 1-48.

[22] Thornton, D. L. (2013): "An evaluation of event-study evidence on the effectiveness of the FOMC's LSAP program: the reasonable person standard", Working Paper No. 2013-033A, Federal Reserve Bank of St. Louis. 
[23] Wright, J. (2012): "What does monetary policy do to long-term interest rates at the zero lower bound?", The Economic Journal 122, 447-466.

[24] Wu, J. C. and F. D. Xia (2014): "Measuring the macroeconomic impact of monetary policy at the zero lower bound", unpublished, The University of Chicago Booth School of Business. 
Table 1: Important Quantitative Easing announcements

\begin{tabular}{|c|c|c|c|}
\hline Date & Program & Event & Content \\
\hline $11 / 25 / 2008$ & QE1 & FOMC statement & LSAP initially announced \\
\hline $12 / 01 / 2008$ & QE1 & Bernanke speech & Suggestion of extending QE to Treasuries \\
\hline $01 / 28 / 2009$ & QE1 & FOMC statement & Fed stands ready to expand QE \\
\hline $03 / 18 / 2009$ & QE1 & FOMC statement & LSAP expanded \\
\hline $08 / 12 / 2009$ & QE1 & FOMC statement & details about LSAP \\
\hline $08 / 27 / 2010$ & QE2 & Bernanke speech & Bernanke sees role for additional QE \\
\hline $09 / 21 / 2010$ & QE2 & FOMC statement & FOMC emphasizes low inflation \\
\hline $10 / 12 / 2010$ & QE2 & FOMC minutes & "additional accommodation" needed \\
\hline $11 / 03 / 2010$ & QE2 & FOMC statement & QE2 announced \\
\hline $09 / 21 / 2011$ & "Twist" & FOMC statement & Maturity Extension Program announced \\
\hline $06 / 20 / 2012$ & "Twist" & FOMC statement & Maturity Extension Program extended \\
\hline $08 / 22 / 2012$ & QE3 & FOMC minutes & "additional accommodation ... warranted" \\
\hline $09 / 13 / 2012$ & QE3 & FOMC statement & QE3 announced \\
\hline $12 / 12 / 2012$ & QE3 & FOMC statement & QE3 expanded \\
\hline
\end{tabular}

Notes: The announcement dates are taken from Fawley and Neely (2013). 


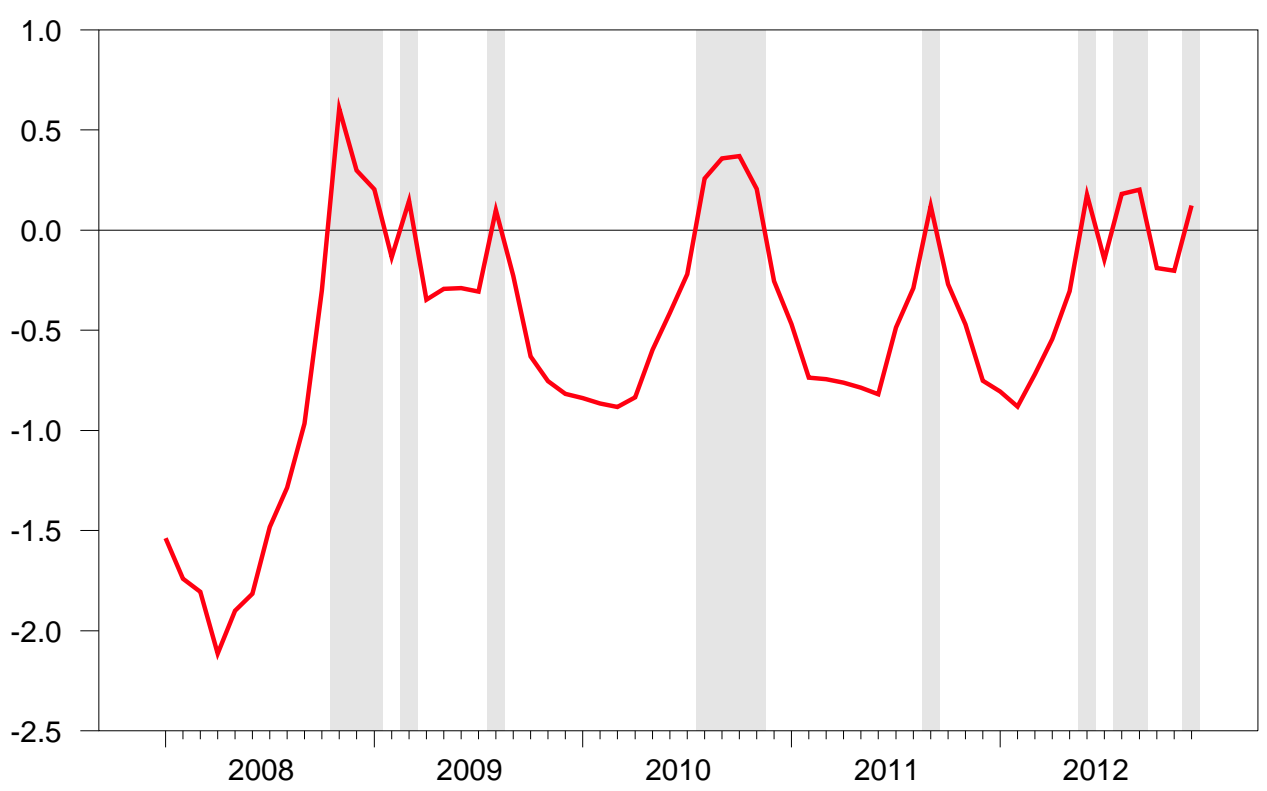

Figure 1: QE announcements (shaded) and latent propensity for QE (red) estimated in model I

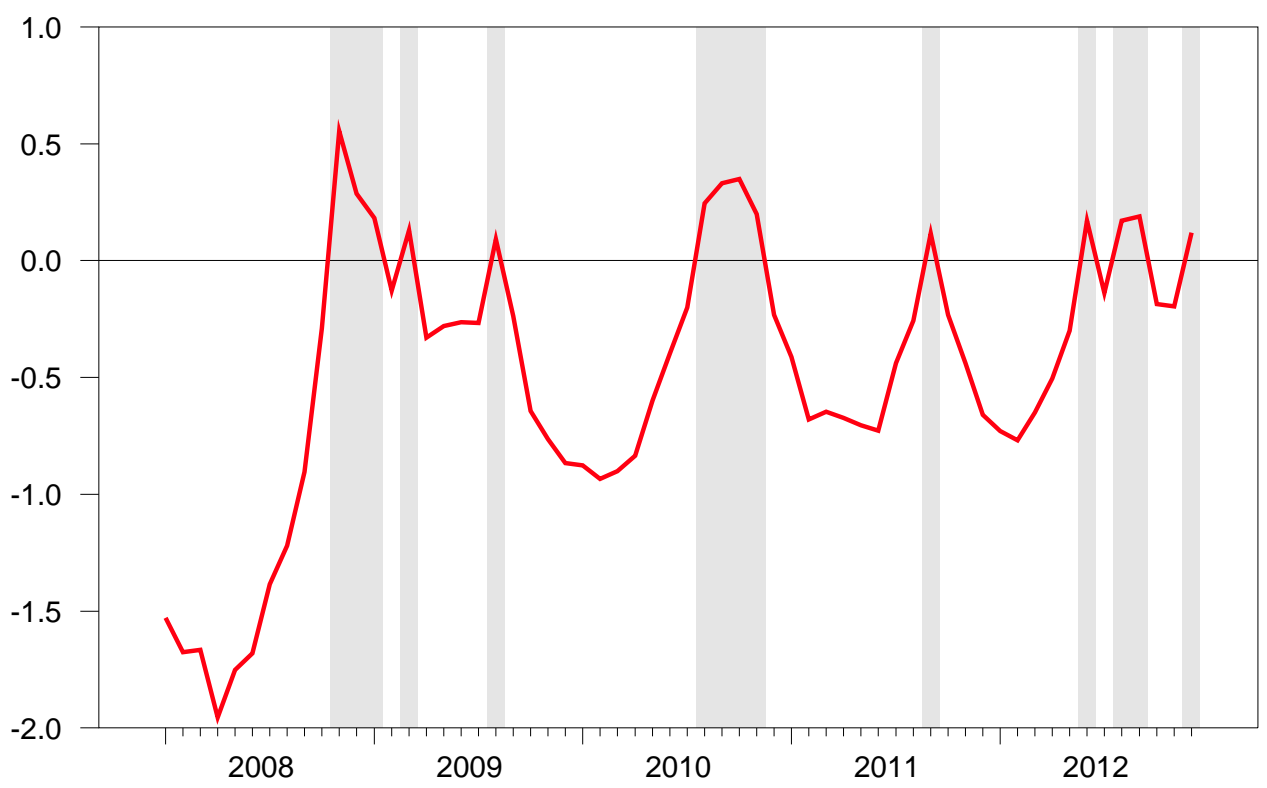

Figure 2: QE announcements (shaded) and latent propensity for QE (red) estimated in model II 


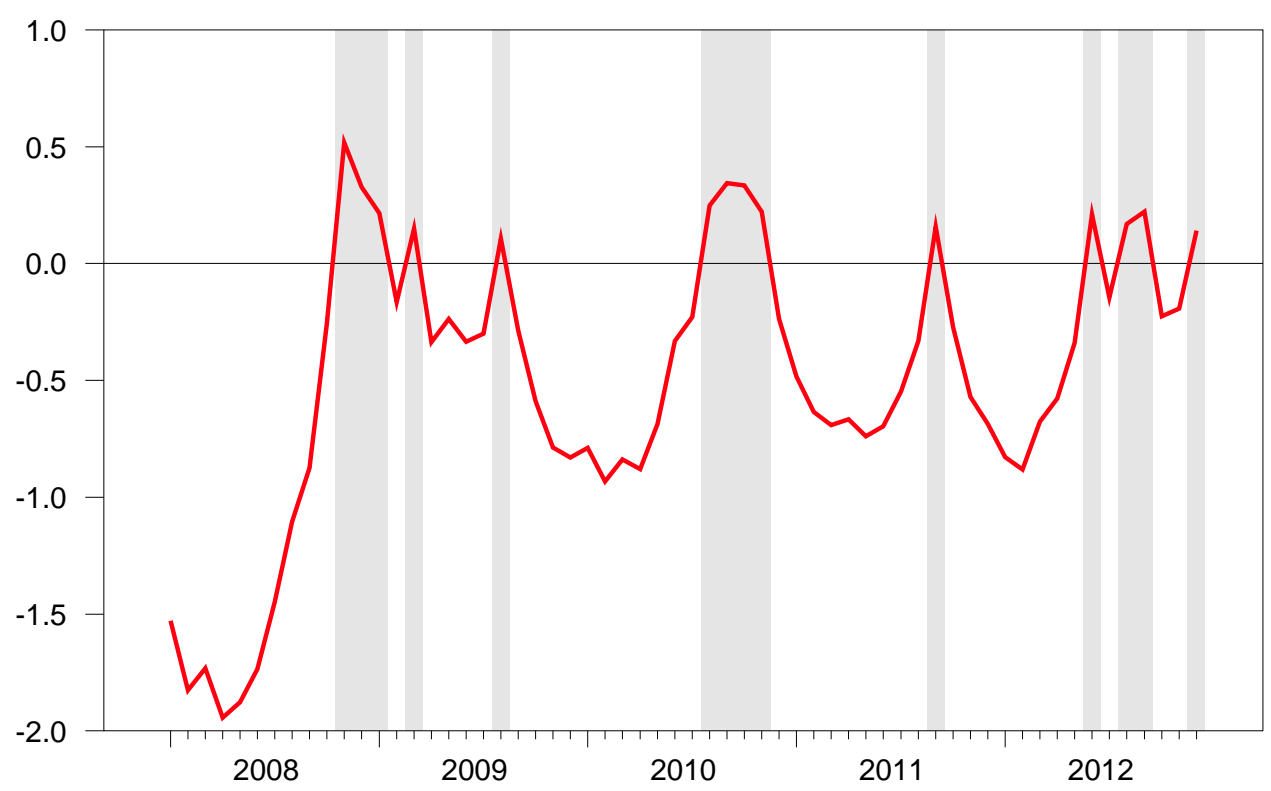

Figure 3: QE announcements (shaded) and latent propensity for QE (red) estimated in model III

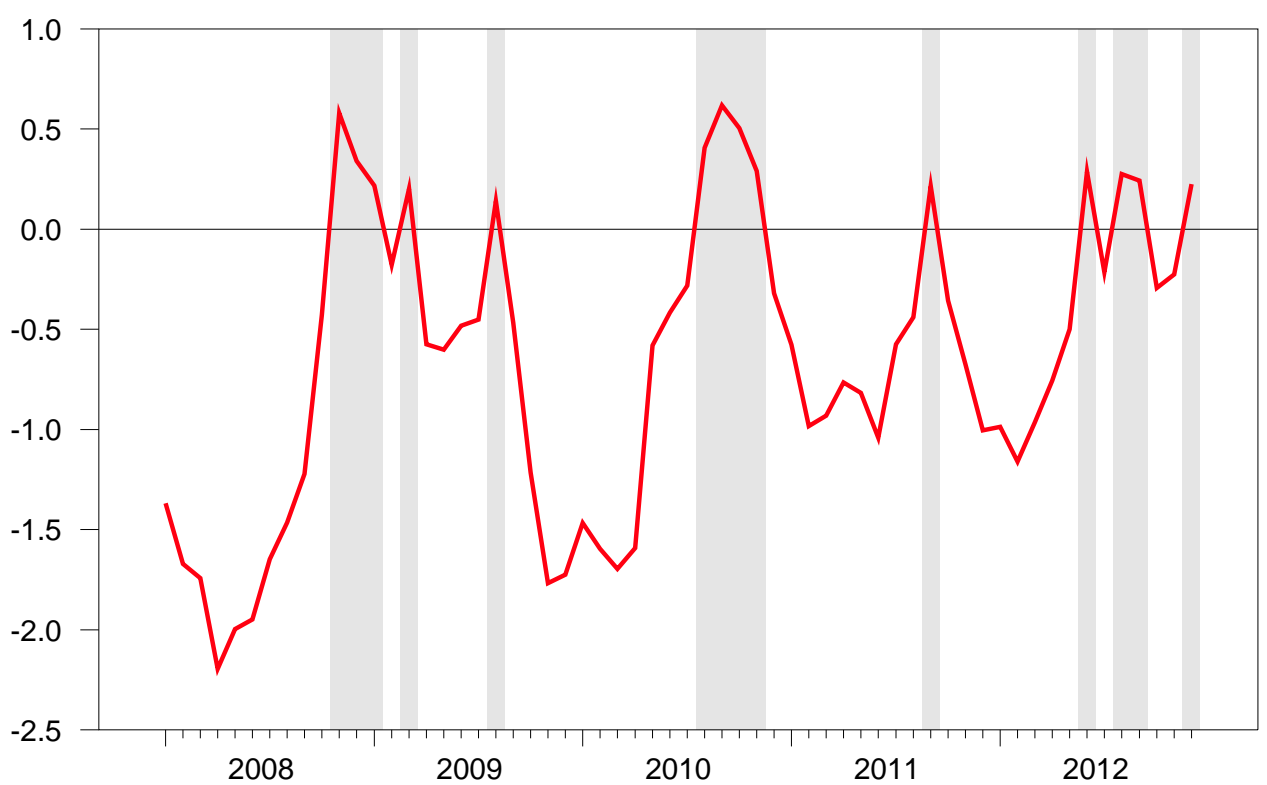

Figure 4: QE announcements (shaded) and latent propensity for QE (red) estimated in model IV 


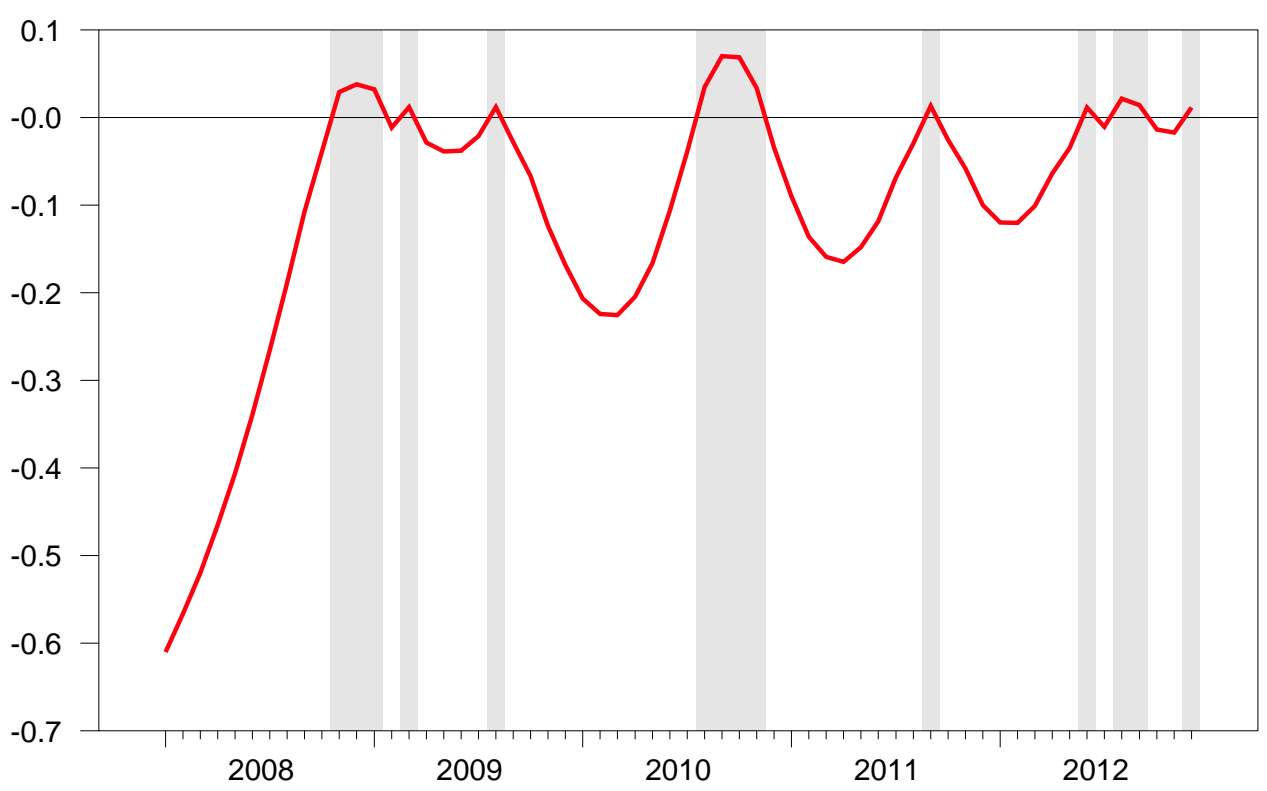

Figure 5: QE announcements (shaded) and latent propensity for QE (red) estimated in model $\mathrm{V}$ 


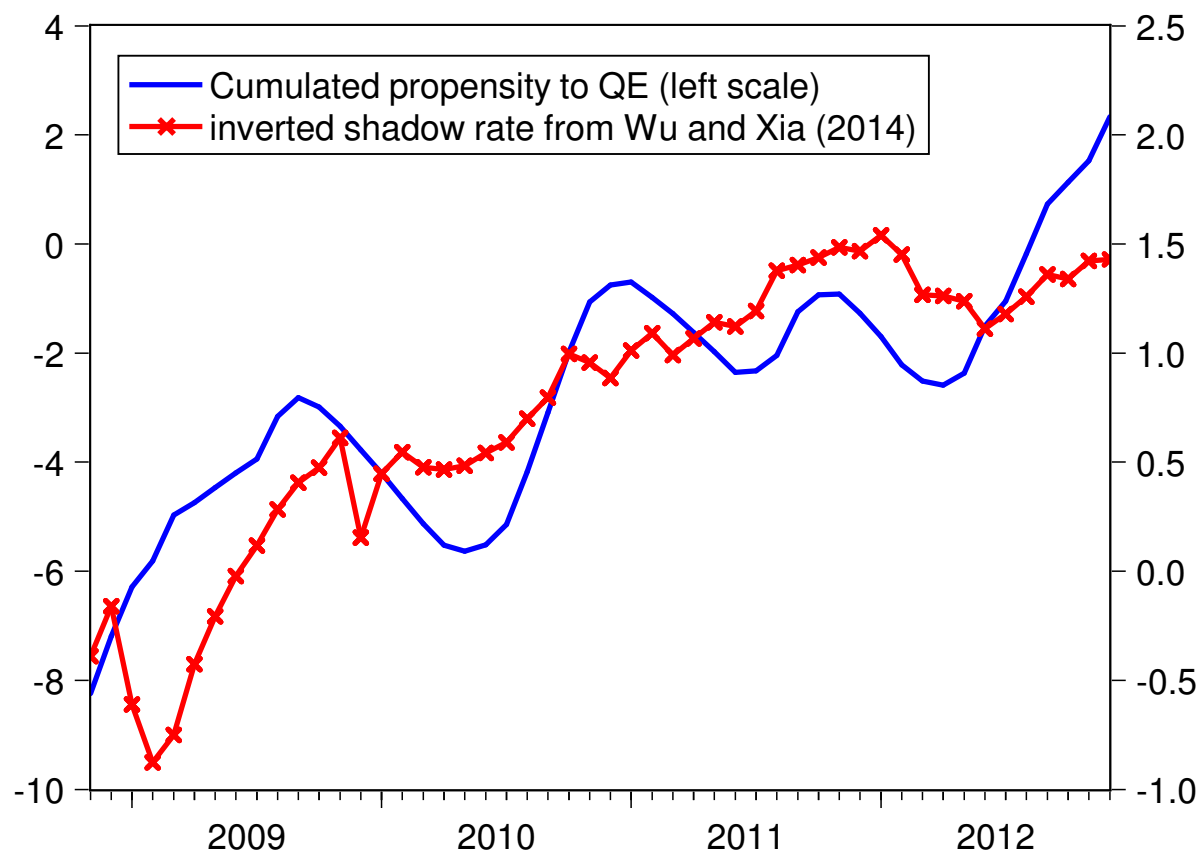

Figure 6: Cumulated latent propensity to $\mathrm{QE}$ and inverted shadow rate from $\mathrm{Wu}$ and Xia (2014) 

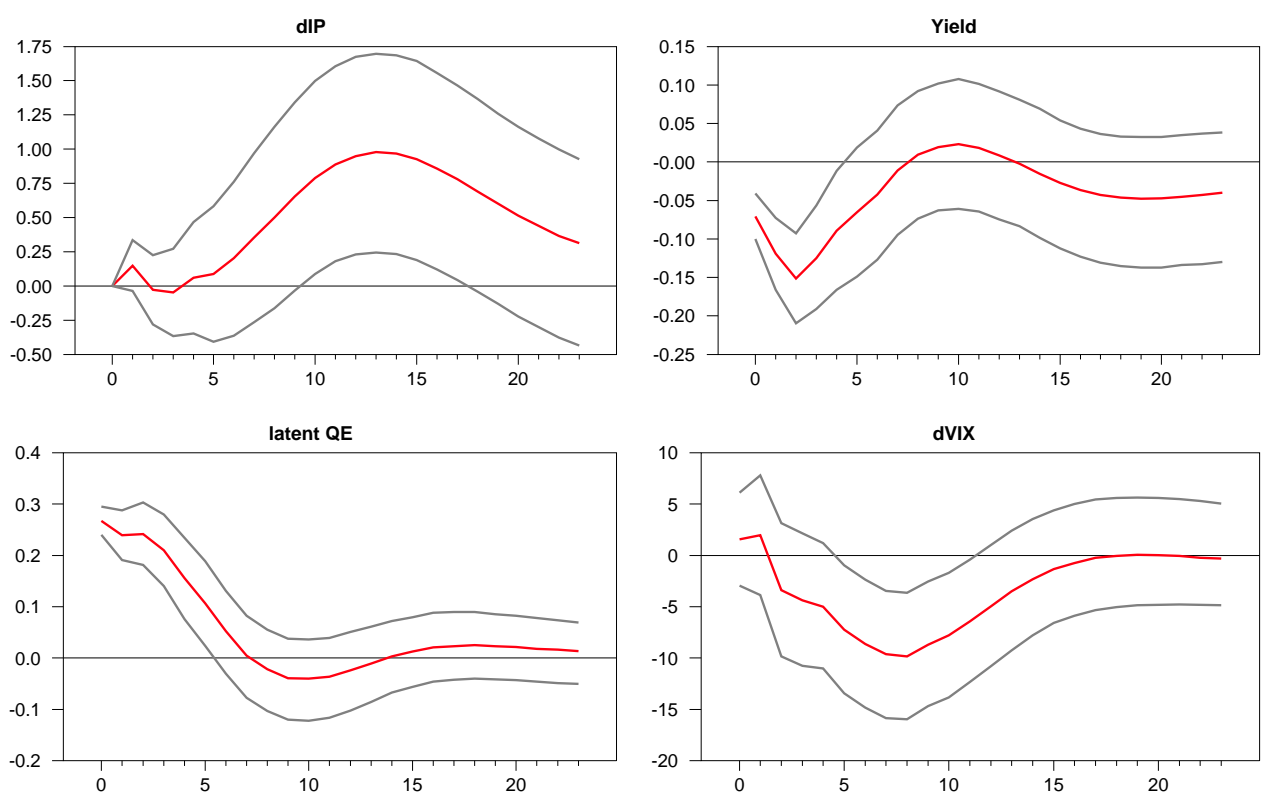

Figure 7: The effect of a shock to the latent propensity to QE in model I
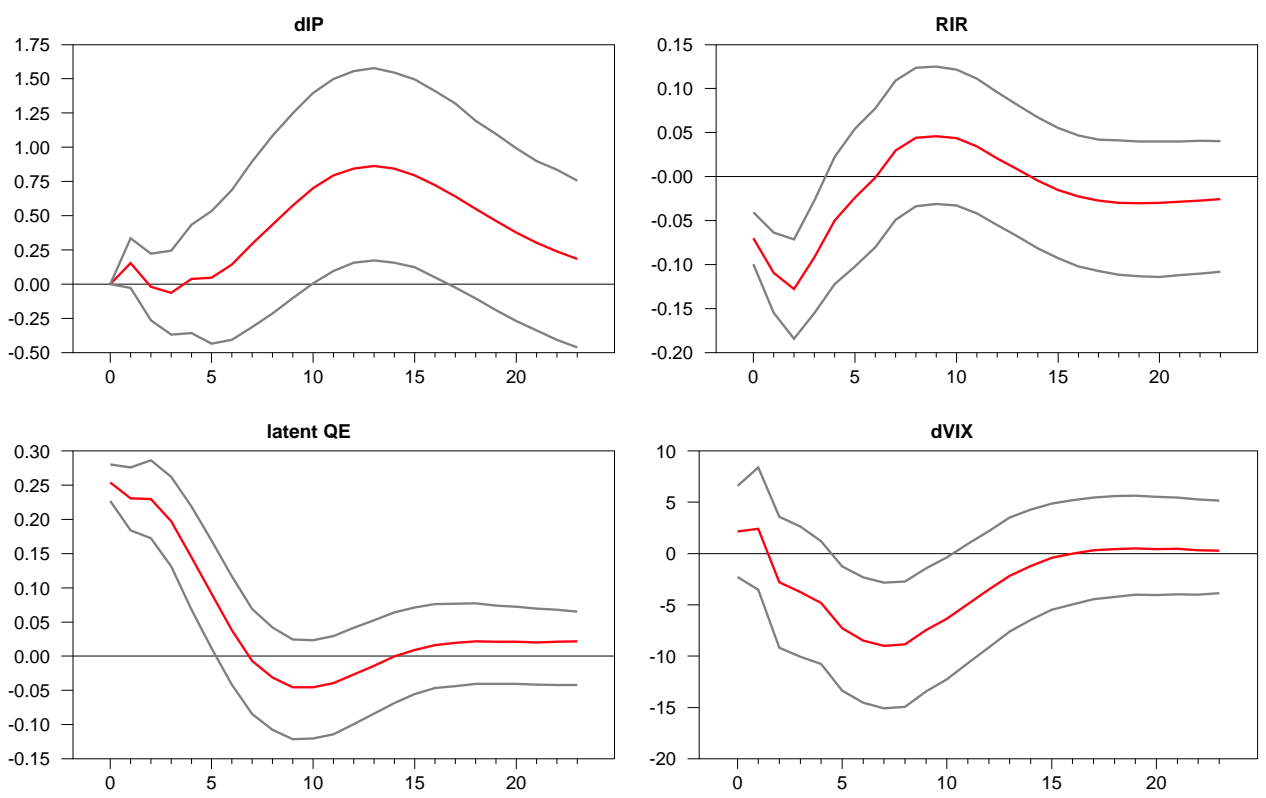

Figure 8: The effect of a shock to the latent propensity to QE in model II 

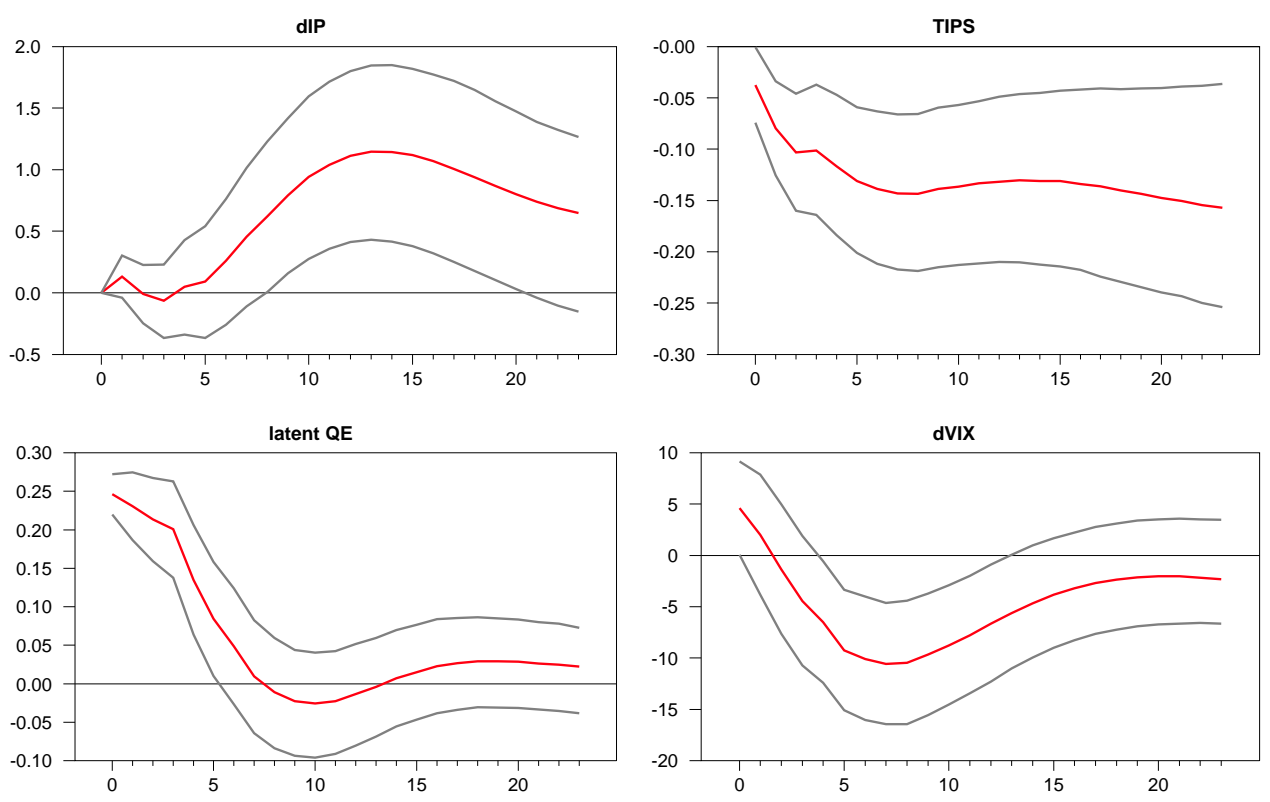

Figure 9: The effect of a shock to the latent propensity to QE in model III
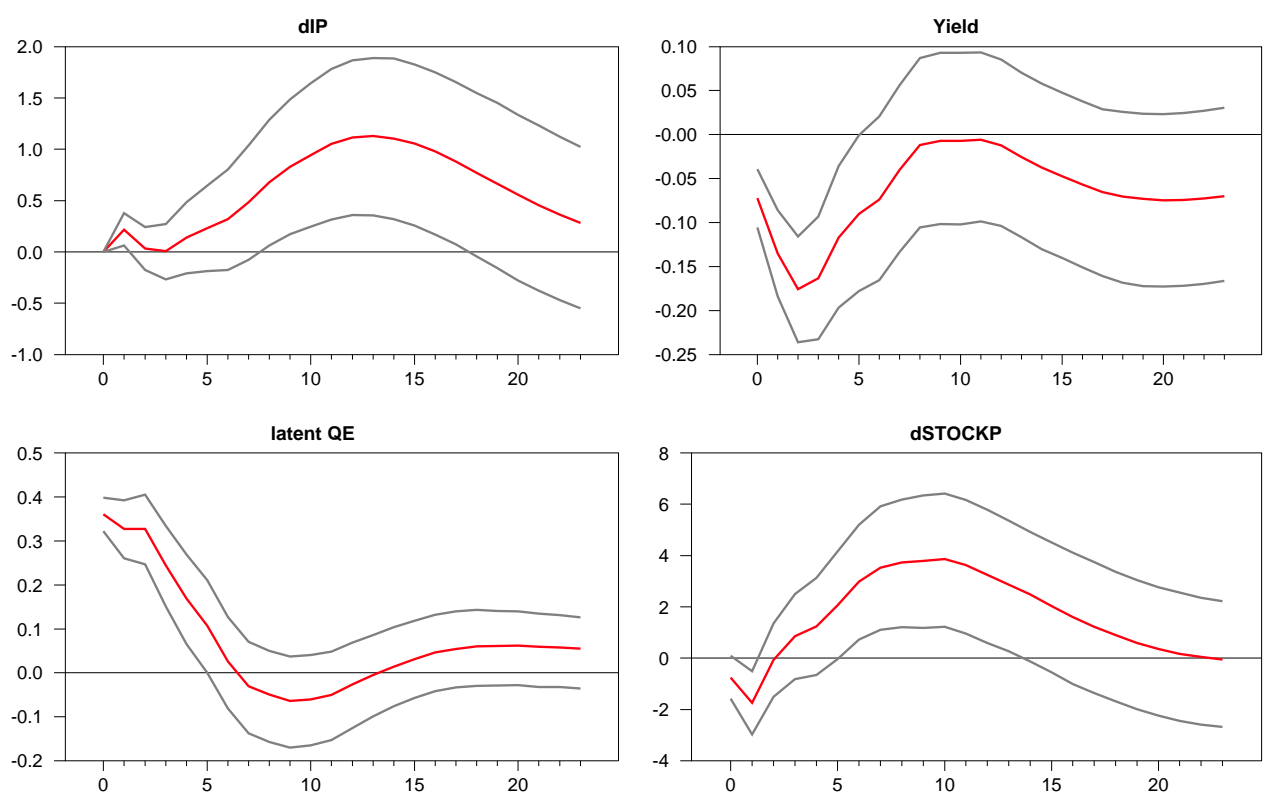

Figure 10: The effect of a shock to the latent propensity to QE in model IV 

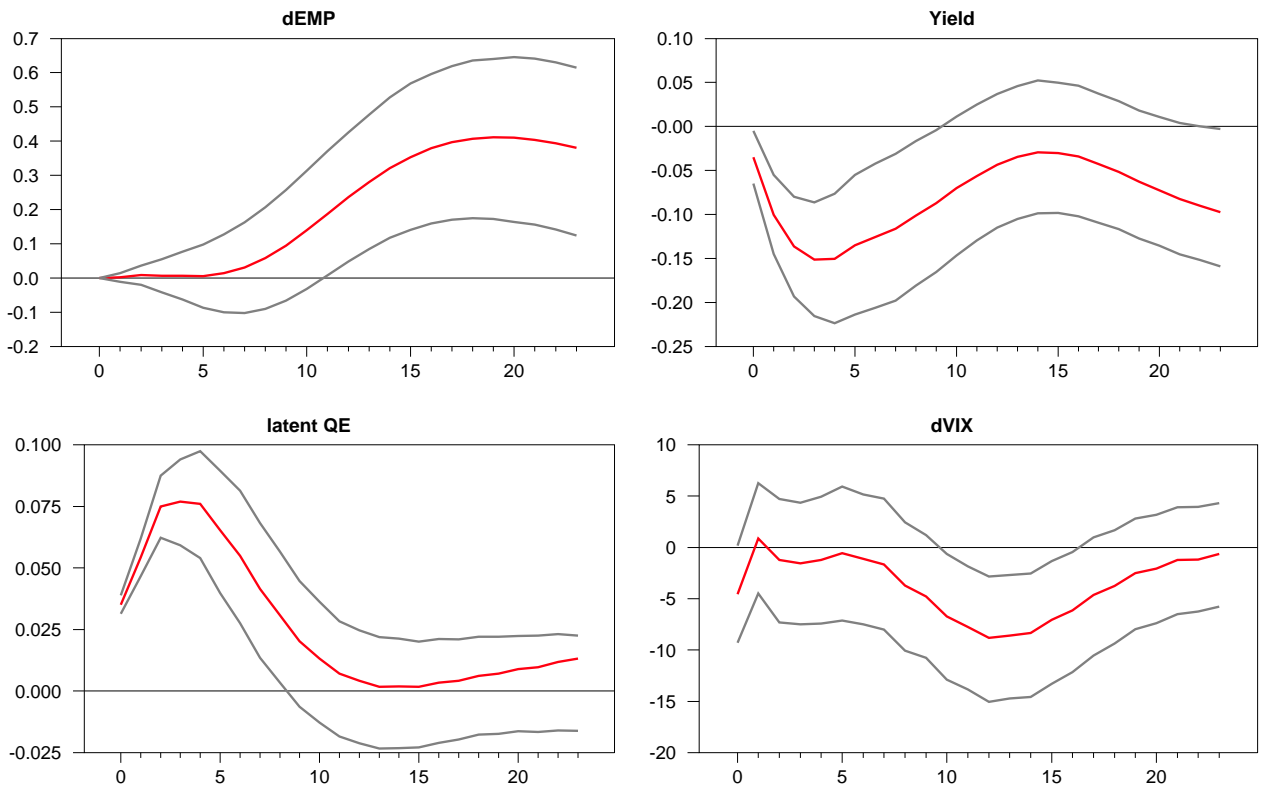

Figure 11: The effect of a shock to the latent propensity to QE in model V 

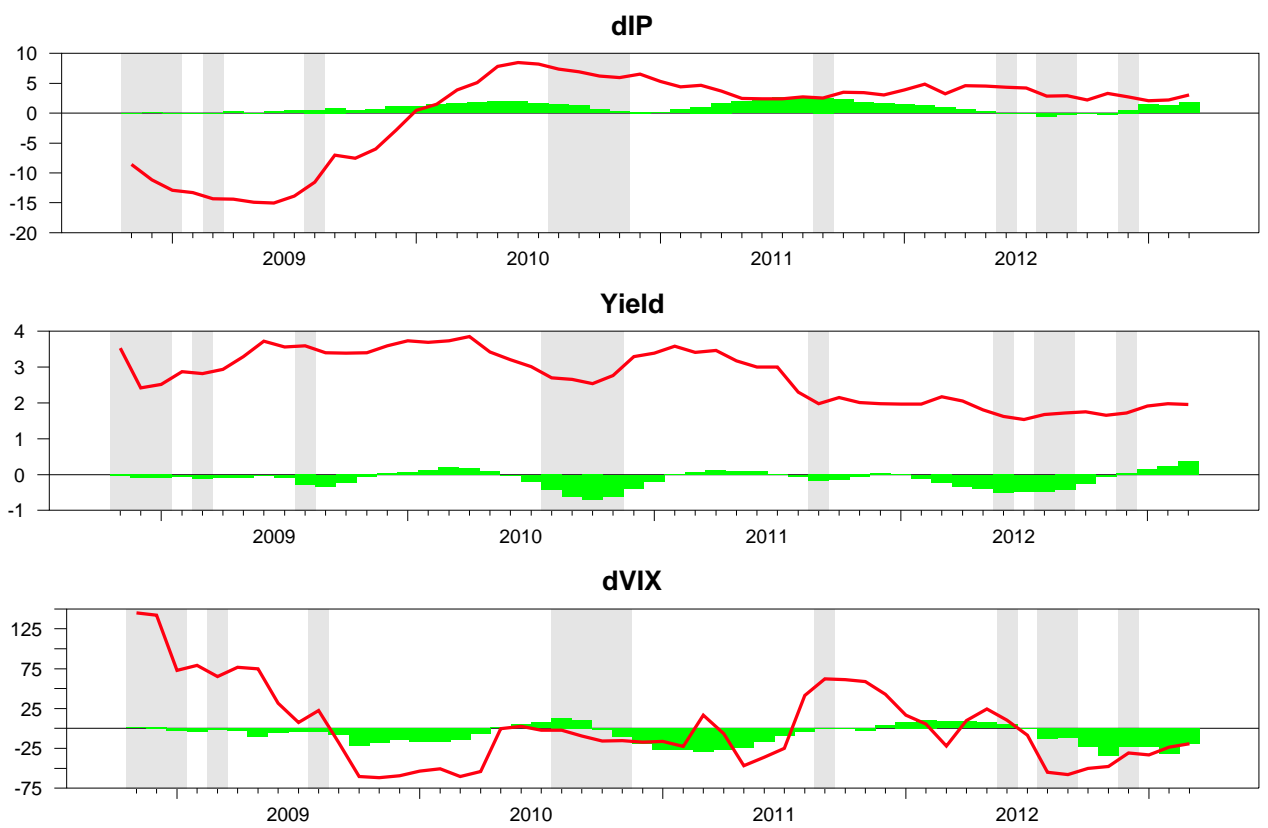

Figure 12: Non-policy variables (red) and fraction explained by QE shocks (green) in model I
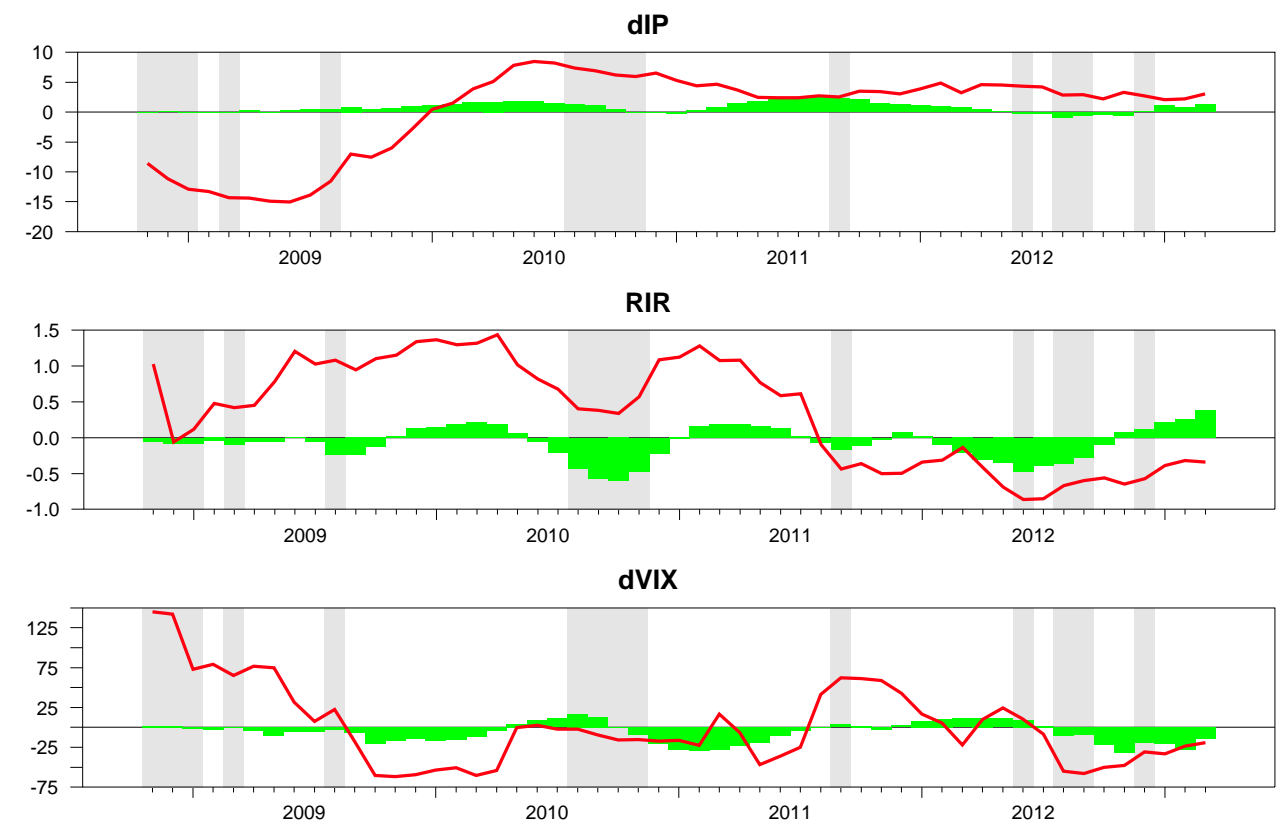

Figure 13: Non-policy variables (red) and fraction explained by QE shocks (green) in model II 

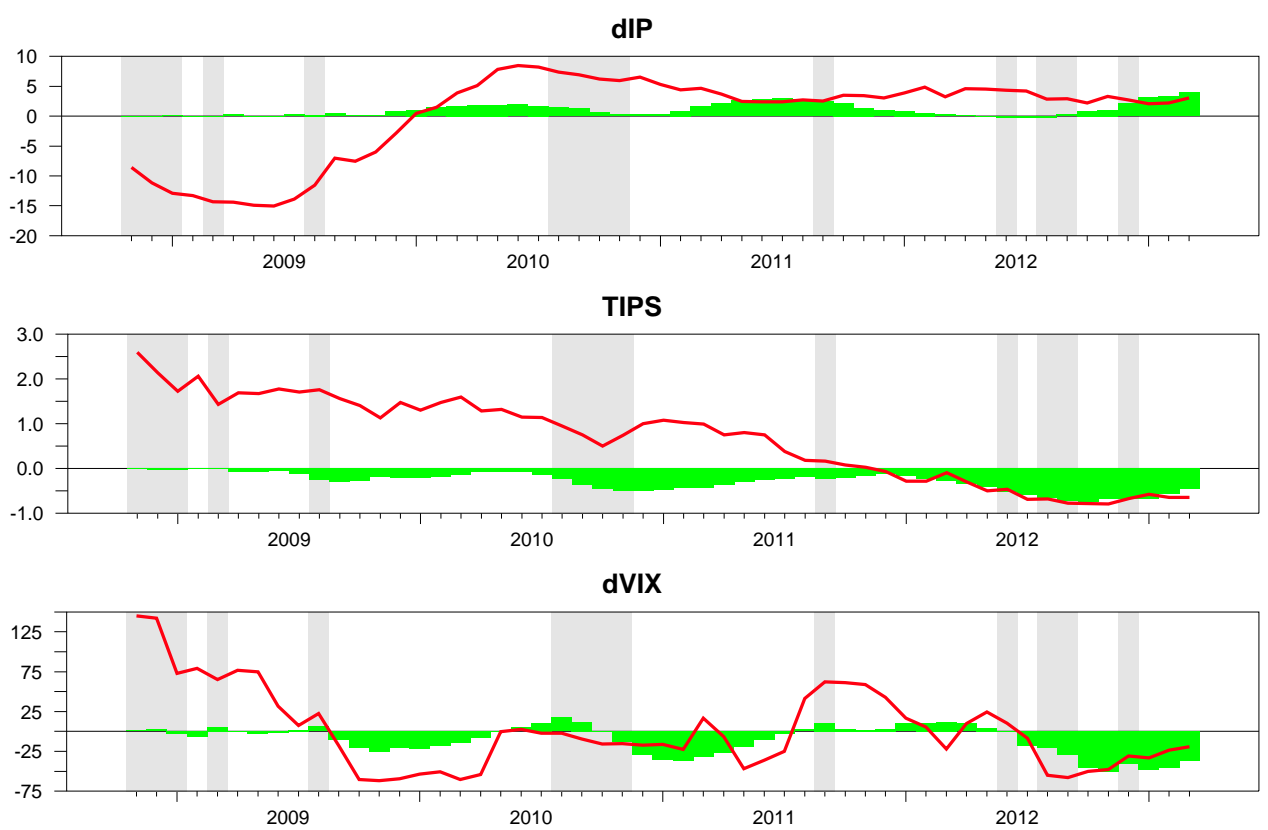

Figure 14: Non-policy variables (red) and fraction explained by QE shocks (green) in model III
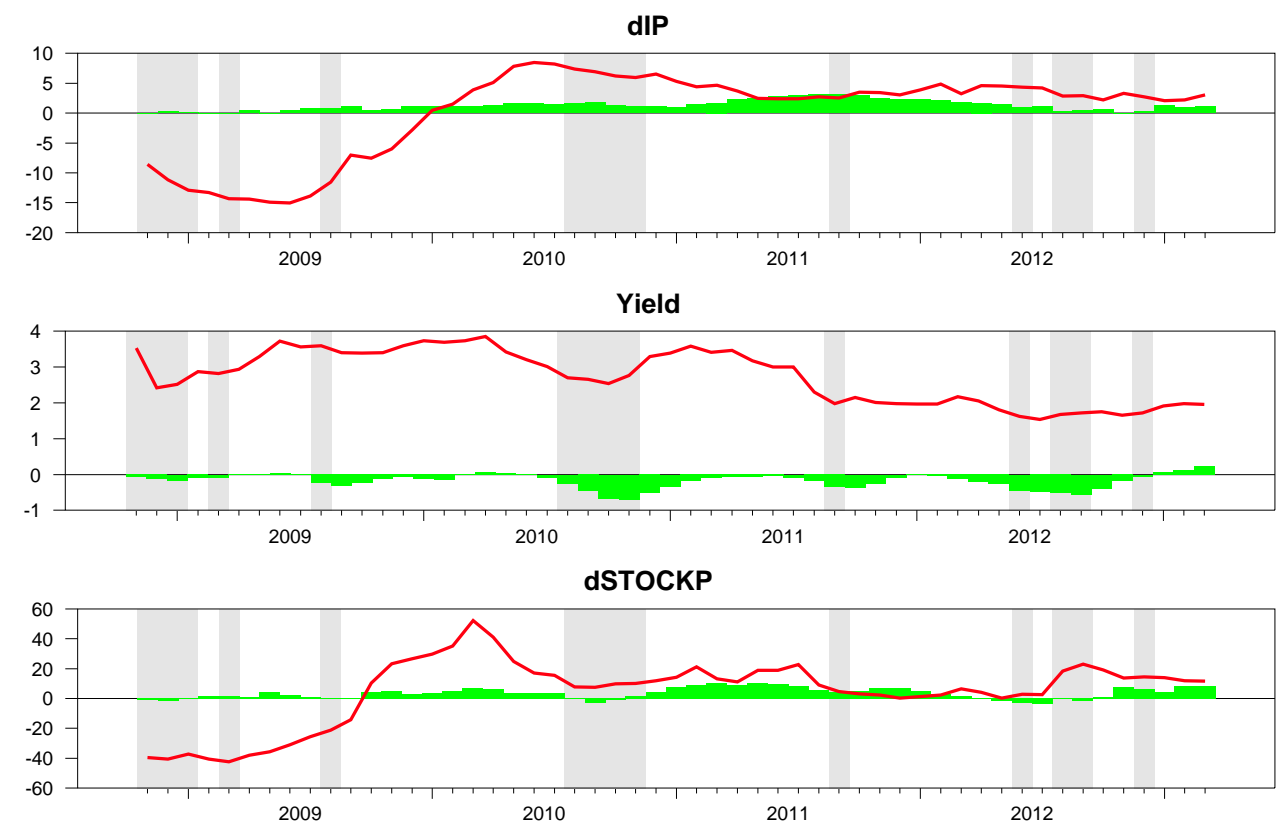

Figure 15: Non-policy variables (red) and fraction explained by QE shocks (green) in model IV 

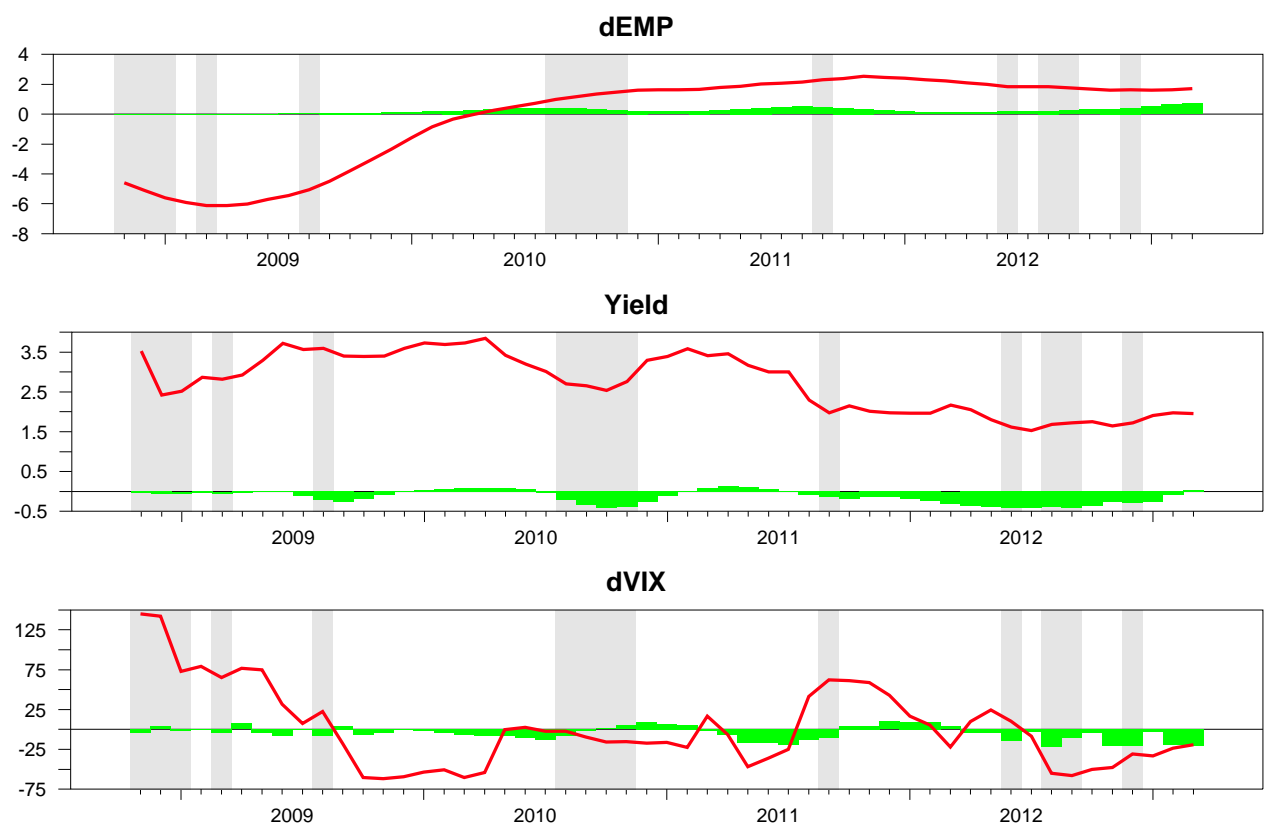

Figure 16: Non-policy variables (red) and fraction explained by QE shocks (green) in model $\mathrm{V}$ 

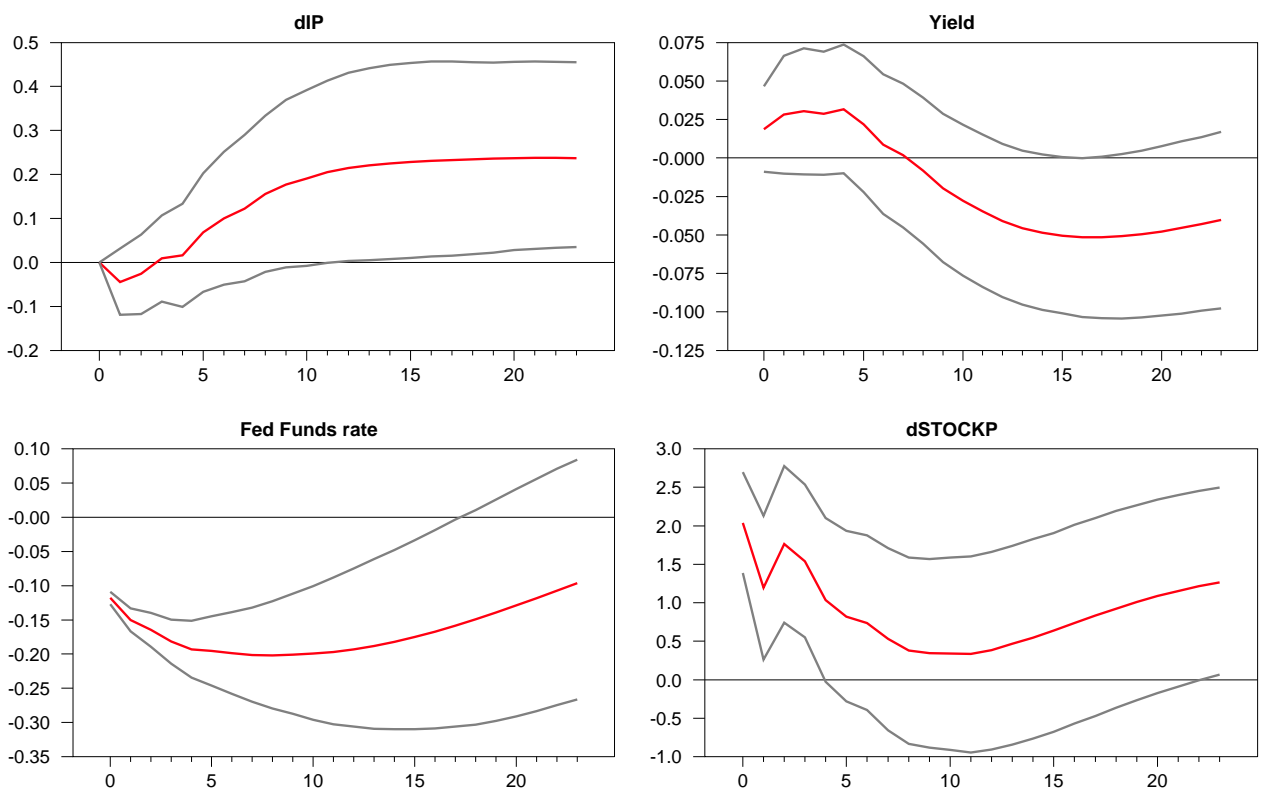

Figure 17: The effect of a conventional policy shock 